\title{
Adverse drug reactions related to potential serious drug interactions in patients with cardiovascular diseases
}

\author{
Eventos adversos a medicamentos relacionados às potenciais interações \\ medicamentosas graves em pacientes com doenças cardiovasculares \\ Eventos adversos a los medicamentos relacionados con posibles interacciones \\ medicamentosas graves en pacientes con enfermedades cardiovasculares
}

How to cite this article: Sobrinho NP, Camos JF, Silva RC. Adverse drug reactions related to potential serious drug interactions in patients with cardiovascular diseases. Rev Gaúcha Enferm. 2020;41:e20190511. doi: https://doi. org/10.1590/1983-1447.2020.20190511 a Universidade Federal do Rio de Janeiro (UFRJ), Escola de Enfermagem Anna Nery, Departamento de Enfermagem Fundamental. Rio de Janeiro, Rio de Janeiro, Brasil.

\section{Natália da Palma Sobrinho Juliana Faria Campos ${ }^{a}$ Rafael Celestino da Silva ${ }^{a}$}

\section{ABSTRACT}

Objective: To assess the occurrence of adverse drug reactions associated with potential serious drug interactions identified in prescriptions of hospitalized patients with cardiovascular disease.

Method: A documentary, quantitative, and cross-sectional research study. Between August and September 2016, ninety-nine prescriptions of patients hospitalized for more than 48 hours in the cardiology ward of a hospital in Rio de Janeiro were analyzed. Drug interactions were evaluated by Micromedex ${ }^{\circledR}$, and adverse events were identified through trackers and analyzed by specialists using the Naranjo Algorithm, by means of descriptive statistics.

Results: Eighteen potential serious interactions were detected in 22 drug pairs, mainly simvastatin $\mathrm{x}$ anlodipine (18\%) and enoxaparin x clopidogrel (18\%). Of the 18 medical records investigated, four trackers were found and three probable adverse events (16.6\%) were defined due to hemorrhagic changes in patients.

Conclusion: Drug interactions are likely to cause harm to the patient, which requires implementing barriers for the safety of the medication system.

Keywords: Medication errors. Drug interactions. Patient safety.

\section{RESUMO}

Objetivo: Avaliar a ocorrência de eventos adversos a medicamentos associados às potenciais interações medicamentosas graves identificadas em prescrições de pacientes hospitalizados com doenç̧as cardiovasculares.

Método: Pesquisa documental, quantitativa, seccional. Foram analisadas entre agosto e setembro de 201699 prescrições de pacientes internados há mais de 48 horas na enfermaria cardiológica de um hospital do Rio de Janeiro. As interações medicamentosas foram avaliadas pelo Micromedex ${ }^{\oplus}$, e os eventos adversos identificados através de rastreadores e analisados por especialistas com uso do Algoritmo de Naranjo, com emprego de estatística descritiva.

Resultados: Foram detectadas 18 potenciais interações graves em 22 pares medicamentosos, principalmente sinvastatina $x$ anlodipino (18\%) e enoxaparina x clopidogrel (18\%). Dos 18 prontuários investigados, foram encontrados quatro rastreadores e definidos três prováveis eventos adversos (16,6\%), por alterações hemorrágicas nos pacientes.

Conclusão: Interações medicamentosas têm probabilidade de causar danos ao paciente, o que requer implementar barreiras para a segurança do sistema de medicação.

Palavras-chave: Erros de medicação. Interações medicamentosas. Segurança do paciente.

\section{RESUMEN}

Objetivo: Evaluar la manifestación de eventos adversos a los medicamentos, asociados con posibles interacciones medicamentosas graves, identificadas en las prescripciones de pacientes hospitalizados con enfermedades cardiovasculares.

Método: Investigación documental, cuantitativa y transversal. Entre agosto y septiembre de 2016, se analizaron 99 prescripciones de pacientes hospitalizados durante más de 48 horas en la sala de cardiología de un hospital de Río de Janeiro. Las interacciones medicamentosas fueron evaluadas por medio de Micromedex ${ }^{\circledR}$, y los eventos adversos fueron identificados a través de rastreadores y analizados por especialistas, con el uso del algoritmo de Naranjo y empleo de estadísticas descriptivas.

Resultados: Se detectaron 18 posibles interacciones graves en 22 pares de medicamentos, principalmente entre sinvastatina $x$ anlodipino (18\%) y enoxaparina x clopidogrel (18\%). Entre los 18 registros médicos investigados, se encontraron cuatro rastreadores y se definieron tres probables eventos adversos (16,6\%) debido a cambios de naturaleza hemorrágica en los pacientes.

Conclusión: Es probable que las interacciones medicamentosas causen daño al paciente, lo que requiere implementar barreras para la seguridad del sistema de medicación

Palabras clave: Errores de medicación. Interacciones farmacológicas. Seguridad del paciente. 


\section{口INTRODUCTION}

In 2017, the World Health Organization launched the document entitled"Patient Safety Challenge on Medication Safety", which addresses weaknesses in health systems that lead to medication errors and serious harms. The global initiative aims to reduce by $50 \%$ serious and preventable harms associated with drugs over the next five years ${ }^{(1)}$.

In this document, medication error is understood as a preventable event, which occurs when weaknesses in medication systems related to infrastructure or human factors affect the prescription, transcription, dispensing, preparation, administration, and monitoring of medication practices, and which can result in severe harm to the patient, the Adverse Drug Event ${ }^{(1)}$.

One of these errors that can cause harm to the patient is drug interaction, an alteration of the pharmacological effects between two or more drugs administered concomitantly, which results in an increase or decrease in therapeutic efficacy or in adverse events caused by these, or even in the onset of new effects ${ }^{(2)}$.

Unwanted drug interactions are a reality in the clinical practice and their occurrence can favor: ineffective therapy, increased length of stay and cost of hospitalization, and even serious events that compromise the patient's life. The main risk factor for the interaction is polypharmacy, that is, the concomitant use of five or more drugs ${ }^{(2-4)}$.

This problem of interactions and their potential impact on the patient is relevant and must be addressed in the field of cardiology, considering the population aging profile and the high rate of morbidity and mortality from cardiac diseases ${ }^{(5)}$. This clientele is often susceptible to the use of multiple medications due to the complex therapeutic regimen. Thus, the polypharmacy used in the treatment of cardiovascular diseases increases the chance of concomitant use of these drugs, which makes this pathological condition a factor associated with drug interactions ${ }^{(6-8)}$.

Therefore, this context alerts to the possibility of the occurrence of adverse events with root causes related to drug interactions, which can compromise the lives of these individuals. The potential harms resulting from drug interactions in patients with cardiac diseases are already pointed out in some studies ${ }^{(2,9)}$.

An example of this can be seen in the investigation of potential drug interactions among patients hospitalized in the Cardiology Department of a tertiary hospital in India over a twelve-month period. A sample of 685 patients was analyzed, most of them with hypertension. The results obtained indicated that $76.49 \%$ of the patients had potential drug-drug interactions, with $53 \%$ of serious interactions.
The most frequent interaction was that between aspirin and clopidogrel (28.62\%), with an increased risk of bleeding for the patient ${ }^{(2)}$.

The occurrence of drug-drug interactions was also high in the survey of hypertensive patients who used a mean of seven drugs. Among the interactions of severe classification, the one that occurred between amlodipine and simvastatin stands out, which had clinical significance due to the risk of myopathy and rhabdomyolysis ${ }^{(9)}$.

In a systematic review on the prevalence of potential drug interactions and those that resulted in harm to the patient during hospitalization, 27 articles published between 2000 and 2016 were included. It was not possible to determine the prevalence of interactions that caused real harm to the patient, as the data were limited. Thus, the authors indicated the need for studies that assess the impacts of interactions on patients ${ }^{(10)}$.

In contrast to such knowledge production on the topic, the research problem starts from empirical observations about the scheduling of medication administration by nurses, which pointed to the lack of criteria in its conduction and to the use of a fixed time schedule, an aspect found in the literature ${ }^{(11-12)}$.

These observations led to the reflection on the overload of drugs administered at certain times, the increased risk of serious drug interactions, and the possibility of adverse drug events linked to these interactions, which negatively impact on the patients' therapeutic process and on their safety.

Thus, the research question was the following: What adverse drug events can be associated with the potential serious drug interactions identified in prescriptions of hospitalized patients with cardiovascular diseases? The obective was the following: to evaluate the occurrence of adverse drug events associated with potential serious drug interactions identified in prescriptions of hospitalized patients with cardiovascular diseases.

The justification for this research is based on the fact that one of the goals of the National Patient Safety Program is to prevent adverse events related to medications by promoting safe practices ${ }^{(13)}$. Therefore, when evaluating the association of serious drug interactions with the occurrence of adverse events, possibilities open up that the knowledge produced may guide the proposition of interventions aimed at safety in the prescription, use, and administration of medications.

\section{METHOD}

A cross-sectional and retrospective research study with quantitative design, developed in two phases, namely: phase 1 , analysis of prescriptions to identify potential serious drug 
interactions based on the scheduling performed by the nurse; phase 2, analysis of the medical records of patients with severe interactions, in search of adverse drug event trackers that could be associated with these interactions.

The study was carried out in a large general hospital located in the city of Rio de Janeiro, a reference for mediumand high-complexity procedures. This institution was chosen because it is a member of the Sentinel Health Surveillance Network, aimed at managing the risk of incidents and adverse events. The locus of the investigation was a clinical unit specialized in cardiology, with 30 beds available for hospitalization.

In this scenario, the medication system is computerized through institutional software, from which the physician selects the medication for prescription. Subsequently, there is the choice of times for the administration of medication by the nurse, also through this electronic system, a necessary condition for the prescription to be sent to the Pharmacy sector. The clinical pharmacist receives the order, evaluates the prescriptions and, if deemed necessary, contacts the physician and/or nurse for clarifications and/or suggestions. Such a computerized system does not have the ability to send automatic alerts regarding the risk of drug interactions.

After such validation of the prescription, the medications are separated for a period of 24 hours in unit doses and sent to the sectors with the printed prescription until $2 \mathrm{pm}$. The nursing team receives these drugs, checks, prepares, and administers them to patients, in addition to recording and monitoring their reactions. There is no satellite stock in the sectors.

The sample consisted of prescriptions, determined from the sample calculation for finite populations, taking the following into account: $95 \%$ confidence level; a sampling error margin of 0.05 ; the percentage of $20 \%$ of drug interactions caused by the nurse's scheduling of hours, based on the literature ${ }^{(14) ;}$ and the universe of eligible prescriptions. This was calculated based on the mean number of patients hospitalized in cardiology and on the days of hospitalization. This resulted in a total of 160 prescriptions generated in one month. After applying the formula, a sample of 99 prescriptions was obtained.

The retrospective cut for analysis of prescriptions was the year 2014, from April to June, a period of hospitalization consensus among the professionals of the institution that there was no seasonal influence on the profile of the patients and the drugs used. As for the time frame, the year before the start of the project was defined; however, as there were difficulties in making the insertion in the field operational, data collection only started in 2016, choosing to maintain the methodological design of the project that obtained a favorable ethical opinion.
In order to capture these prescriptions, a list of patients hospitalized in the specified period was made, from access to the admission record and hospital discharge book at the Documentation Service, in which it was possible to identify 150 patients.

The eligibility criteria for drug prescriptions for inpatients with cardiovascular diseases were the following: over 18 years of age, of both genders; with a reason for hospitalization in the cardiology ward related to cardiovascular diseases; in pharmacological therapy with at least two prescription drugs; and hospital stay longer than 48 hours.

The verification of compliance with the eligibility criteria occurred from the reading of the patient's medical record, which resulted in the pre-selection of 140 medical records that met these criteria. The medical records were then numbered sequentially, with random numbers being drawn until reaching the total of the study sample, 99 prescriptions. After the selection of medical records by means of a draw, there was an analysis of the drug prescription referring to the 48 hours of hospitalization, a period in which the prescription was already reviewed by a cardiologist and composed of the drugs necessary to achieve the therapeutic results.

In phase 1, the survey of medications in electronic prescriptions was based on a structured instrument. The instrument consisted of the following items: sociodemographic variables of the patients; variables on clinical aspects; all prescription drugs; and the schedule proposed by the nurse for medication administration.

Then, the analysis of potential interactions was performed using the Micromedex software, through access to the Capes Journal Portal. For this purpose, the drug interaction tab was selected and the drugs were submitted to the software using the generic name grouped by pairs, based on the scheduling performed by the nurse.

The software identified the occurrence of the interaction and classified it according to type, severity, level of evidence, and potential clinical repercussions, with the time of onset. In the present study, the analysis focused on drug-drug interactions of the pharmacodynamic type, which alter the biochemical or physiological effect of the drug; and classified as severe, an interaction that can be life-threatening or require medical intervention to minimize or avoid serious adverse effects ${ }^{(15)}$.

As for the level of evidence of the drug interaction, it was classified as: excellent, when controlled studies consistently demonstrated the interaction; good, evidence that strongly indicates the interaction, although there is lack of controlled studies; and reasonable level, at which the available studies are unsatisfactory, but the pharmacological aspects are sufficient to assert the occurrence of the interaction ${ }^{(15)}$. 
For the data collection of phase 2, the list of trackers proposed for surveillance of adverse events related to medications by the Institute for Healthcare Improvement $(\mid \mathrm{HI})^{(16)}$ was used. Considering the research objective, an adaptation of this list was made based on the interactions identified in phase 1 of the study, in an attempt to refine the trackers based on the analysis of the clinical repercussions that such interactions could cause.

Decision-making regarding the trackers to be included took place in a meeting of the researcher with two members of a research group with experience in the theme, in which there was a presentation of the analysis of the clinical repercussions of the identified serious interactions and, from that, in a consensual and verbal way, it was decided on the criteria to be adapted.

The trackers used were the following: vitamin $\mathrm{K}$; metoclopramide; flumazenil; naloxone; promethazine; calcium polystyrenesulfonate; prothrombin time (PTT) > 100 seconds; INR $>6$; serum glucose $<50 \mathrm{mg} / \mathrm{dL}$; serum creatinine increase; serum potassium increase; change in blood pressure; change in respiratory rate; change in heart rate; nausea, vomiting and diarrhea; sedation, lethargy and falling; rash; abrupt withdrawal of the medication; and transfer to Intensive or Semi-Intensive Care Unit.

The next stage was the analysis by the researcher of the medical records of patients who had the occurrence of potential serious interactions. In this phase, the medical record of the entire hospitalization period was analyzed, observing the following sections: registration of physicians and nurses; laboratory tests; and use of specific medications; guided by a data collection instrument that included: drug pair with severe interaction and clinical repercussion established by Micromedex; presence of the tracker; and clinical evidence identified in the medical record related to the tracker.

The medical records of the suspected cases were separated from the identification of a single tracker and forwarded for final analysis by a panel of specialists ${ }^{(16-17)}$. The panel was attended by members of the Patient Safety Nucleus in the research field: two nurses, a cardiologist, a clinical pharmacist and the researcher; specialists chosen based on professional experience (over five years of clinical care practice) and on their experience in the monitoring of adverse events.

At first, the meeting took place between the researcher and all the members of the nucleus for the expository presentation of the research project, its objectives, and the $\mathrm{IHI}$ methodology. After the identification of serious interactions and the active search for trackers in medical records, there was a meeting for the panel's final decision on the adverse event.

The expert panel meeting took place so that each team member initially carried out an individual analysis based on the data presented by the researcher in an expository and written manner and, immediately after that, a group analysis was carried out for the final decision regarding the occurrence of the adverse event.

During the exposure of suspected cases, data on the patient's demographic and clinical profile were presented to guide the panel of specialists, such as: age, diagnosis of hospitalization, comorbidities, trajectory of hospitalization, days of hospitalization, prescription drugs analyzed in Micromedex, time of drug use, drug pairs with severe interaction identified by the software, clinical repercussions of the drug interaction, identified tracker, presence of objective evidence of the repercussion, and possible adverse reactions of the drugs used. The complete medical records of the suspected cases were made available for consultation during the meeting.

In the analysis of the suspected cases, the Naranjo Algorithm was used to determine the causality in relation to the interaction and the adverse event. This consists of a probability scale that includes the chronological sequence between the administration of the suspected drug and the onset of the clinical condition, the plausibility of the causality relationship (taking into account the previous description of the reaction in the literature or the pharmacological properties of the drug), the outcome of the reaction after drug withdrawal, the recurrence of the clinical condition described with the re-administration of the suspected drug or after re-exposure to it, and the existence of alternative causes ${ }^{(18)}$.

In this study, the Naranjo algorithm was adapted considering the drug pair as the suspect drug. The algorithm establishes a score from ten objective questions. At the end, a classification is attributed based on the score obtained, in which less than or equal to zero means that the event is doubtful; from 1 to 4, possible; from 5 to 8 , the adverse event is categorized as probable; and, if equal to or greater than 9 , as defined ${ }^{(18)}$.

For the organization of the data and its statistical analysis, the Excell ${ }^{\otimes}$ software was used. In the characterization data, the discrete variables were analyzed using descriptive statistical measures of absolute and relative frequency, and the continuous variables, using measures of central tendency. For the analysis of drug interactions and adverse events, descriptive statistical measures were calculated as absolute and relative frequency.

Data collection took place from August to September 2016 after the study was approved by the institution's Research Ethics Committee, CAAE: 56849816.4.0000.5238, under opinion number: 1612961 . As this is a research study with secondary data, the Free and Informed Consent Term was waived. 


\section{RESULTS}

Regarding the demographic and clinical profile of patients with cardiovascular diseases, of the 99 prescriptions, $59 \%$ referred to male patients and $41 \%$ to femalepatients, with a mean age of $71.7( \pm 15.1)$ years old. In relation to the female gender, a mean of 75.8 was observed, whereas for the male gender, the mean was 67.2 years old. The most prevalent medical diagnoses according to the ICD-10 were Congestive Heart Failure (22.2\%) and Acute Myocardial Infarction (20\%). The hospitalization outcome was $91.9 \%$ for hospital discharge and $8 \%$ for death.

In 18 prescriptions, 22 drug-drug interactions with potential for serious harm were detected, which represented a mean of 1.22 serious drug interactions per prescription. All the prescriptions involved $(n=18)$ had five or more prescription drugs, a mean of 13.33 drugs per prescription, which characterized patients using polypharmaceuticals.

The drugs involved in potential drug interactions for serious harm were the following: amiodarone $(n=5)$, simvastatin $(n=5)$, amlodipine $(n=4)$, clopidogrel $(n=4)$, enoxaparin $(n=4)$, digoxin $(n=2)$, ranitidine $(n=2)$, risperidone $(n=2)$, diltiazen $(n=1)$, carvedilol $(n=1)$, cilostazol $(n=1)$, potassium chloride $(n=1)$, spironolactone $(n=1)$, enalapril $(n=1)$, metoprolol $(n=1)$, omeprazole $(n=1)$, ticagrelor $(n=1)$, and warfarin $(n=1)$. The pairs in which the interactions occurred and the level of evidence are shown in Chart 1.

Based on the potential serious drug interactions detected, eighteen patient records were investigated. With regard to the total of twenty trackers employed, four were identified in three records, namely: abrupt withdrawal of the drug, increased INR, and elevation of creatinine and potassium. From this identification, the tracker was related to the severe interaction present in the patient's prescription, its clinical repercussions, and the time of onset indicated by Micromedex.

Among the drug classes, anticoagulants were the drugs most related to adverse events. As for the process of identifying the trackers in the medical records, in the case of abrupt withdrawal of the medication, objective evidence of possible clinical repercussions related to the interaction was first noticed in the nursing team's records, which directed to the investigation about the discontinuation of the medication in the prescription. As a result, Clopidogrel was discontinued.

The three trackers based on changes in laboratory tests, on the other hand, were noted first in the medical record, which led to the investigation in the laboratory tests section for details, which confirmed the changes.

With the identification of the trackers in the medical records, the suspected cases were taken to the Expert Panel, with analysis of the data: the diagnosis and procedures submitted; hospitalization time; medications used in the hospital with start and end dates; serious drug interaction identified, level of evidence of the interaction, its clinical repercussions and time of onset; adverse reactions associated with the drug when administered alone; tracker identified in the medical record with start date of the change, and possible objective evidence of the harm.

Thus, the conclusion obtained were three probable cases of adverse drug events associated with serious drug interactions, in which implications for patient safety were evidenced, according to the sum of the scores attributed to the ten questions used with the Naranjo Algorithm application, as shown in Chart 2.

The demographic and clinical characteristics of the patients who had the probable adverse event were the following: two female patients and one male; with a mean age of 81.33 years old, SD: 4.72; inpatient diagnoses of acute myocardial infarction (1), atrial flutter (1), and unstable angina (1); mean hospital stay of 11.66 days; all with an outcome of hospital discharge. The patients had comorbidities, mainly: arterial hypertension, diabetes mellitus, dyslipidemias, and cardiac arrhythmia.

\section{DISCUSSION}

The frequency of potential serious interactions detected in the study was $38.6 \%$; the main drug pairs were enoxaparin + clopidogrel and simvastatin + amlodipine, and the drug classes were antihypertensive, antiarrhythmic, antiplatelet agents, statins, and anticoagulants; serious drug interactions occurred in prescriptions with more than five drugs.

Such results are similar to those of international research studies in the specialty of cardiology, which point to a frequency of serious interactions ranging from $30 \%$ to $86 \%$, polypharmacy as a risk factor for interactions, and anticoagulants, antiplatelet agents, and statins as the main classes involved in interactions ${ }^{(19-21)}$.

In one, it was sought to identify drug-drug interactions in patients admitted to cardiac intensive care units in two tertiary hospitals in Pakistan, subsequently comparing the prevalence of these interactions. 260 patients from each hospital who had been hospitalized for at least 24 hours were included, most of them diagnosed with myocardial infarction ${ }^{(19)}$.

In the first institution, 1,295 interactions were identified and $96.5 \%$ of the patients had at least one interaction $(45.2 \%$ severe). In the second institution, 1,253 potential interactions occurred, with $95.7 \%$ of the patients having at least one interaction (45.7\% severe). The drug pairs with the most frequent interactions were the follwoing: aspirin + clopidogrel, 


\begin{tabular}{|l|l|l|c|c|}
\hline Medication 1 & Medication 2 & Documentation & N & \% \\
\hline Simvastatin & Amlodipine & Good & Reasonable & 18 \\
\hline Enoxaparin & Clopidogrel & Reasonable & 2 & 9 \\
\hline Amiodarone & Ranitidine & Good & 2 & 9 \\
\hline Risperidone & Simvastatin & Good & 1 & 4.6 \\
\hline Diltiazen & Metoprolol & Good & 1 & 4.6 \\
\hline Enalapril & Potassium chloride & Good & 1 & 4.6 \\
\hline Cilostazol & Omeprazole & Excellent & 1 & 4.6 \\
\hline Amlodipine & Clopidogrel & Reasonable & 1 & 4.6 \\
\hline Enoxparina & Warfarin & Reasonable & 1 & 4.6 \\
\hline Carvedilol & Digoxin & Good & 1 & 4.6 \\
\hline Amlodipine & Amiodarone & Excellent & 1 & 4.6 \\
\hline Simvastatin & Amiodarone & Reasonable & Good & 4.6 \\
\hline Ticagrelor & Amiodarone & & $\mathbf{2 2}$ & $\mathbf{1 0 0}$ \\
\hline Digoxin & Spironolactone & & & 4.6 \\
\hline TotaL & & & 1 & 4 \\
\hline
\end{tabular}

Chart 1 - Severe drug interactions identified in the prescriptions analyzed Source: Research data $n=$ Number of times that the drug pair was detected by the Micromedex software

\begin{tabular}{|c|c|c|c|c|}
\hline Drug pair & $\begin{array}{l}\text { Clinical repercussions } \\
\text { wand time of onset }\end{array}$ & $\begin{array}{l}\text { Identified } \\
\text { tracker }\end{array}$ & $\begin{array}{l}\text { Evidence of the event } \\
\text { identified }\end{array}$ & $\begin{array}{l}\text { Cause of the } \\
\text { adverse event }\end{array}$ \\
\hline $\begin{array}{l}\text { Enoxaparine } \\
+ \text { Clopidogrel }\end{array}$ & $\begin{array}{l}\text { Increase in the risk } \\
\text { of bleeding; } \\
\text { Time: not specified }\end{array}$ & $\begin{array}{l}\text { Discontinuation } \\
\text { of clopidogrel; }\end{array}$ & $\begin{array}{l}\text { Hematomas in the } \\
\text { abdomen and lower limbs; } \\
\text { and increased length } \\
\text { of hospital stay }\end{array}$ & $\begin{array}{c}\text { Probable } \\
\text { Naranjo score }=7\end{array}$ \\
\hline $\begin{array}{l}\text { Simvastatine } \\
+ \text { Amlodipin } \\
\text { Enoxaparine } \\
\text { + Clopidogrel }\end{array}$ & $\begin{array}{c}\text { Increased risk of myopathy, } \\
\text { including rhabdomyolysis; } \\
\text { Time: fast } \\
\text { Increase in the risk } \\
\text { of bleeding; } \\
\text { Time: not specified }\end{array}$ & $\begin{array}{l}\text { Increase in } \\
\text { creatinine } \\
\text { and potassium; }\end{array}$ & $\begin{array}{l}\text { Significant hematuria } \\
\text { and edema of upper and } \\
\text { lower limbs (suspected } \\
\text { rhabdomyolysis); increased } \\
\text { length of hospital stay }\end{array}$ & $\begin{array}{c}\text { Probable } \\
\text { Naranjo score }=7\end{array}$ \\
\hline $\begin{array}{l}\text { Enoxaparine } \\
+ \text { Warfarin }\end{array}$ & $\begin{array}{l}\text { It can result in a higher risk } \\
\text { of hemorrhage; } \\
\text { Time: not specified }\end{array}$ & Increase in INR; & $\begin{array}{l}\text { Hematomas in upper } \\
\text { limbs, lower limbs } \\
\text { and epistaxis; }\end{array}$ & $\begin{array}{c}\text { Probable } \\
\text { Naranjo score }=6\end{array}$ \\
\hline
\end{tabular}

Chart 2 - Analysis of the suspected cases of adverse drug events associated to severe interactions Source: Research data 
aspirin + enoxaparin, and clopidogrel + enoxaparin, all with increased risk of bleeding. The interactions were associated with the number of medications prescribed ${ }^{(19)}$.

In another analysis developed on drug-drug interactions in cardiac intensive care units, the mechanism and severity of the interactions were evaluated, investigated for a period of six months. The sample consisted of 500 patients, $58.6 \%$ of them with Acute Coronary Syndrome ${ }^{(20)}$.

Of the 2,849 interactions, $71.9 \%$ were considered as significant and $3.26 \%$ as severe. The pairs that most interacted were the following: aspirin + clopidogrel $(16.5 \%)$, pantoprazole + clopidogrel (9.8\%), ramipril + aspirin (9.7\%), and aspirin + heparin (7.3\%). There was a correlation between the number of medications and the patients'age with the interactions ${ }^{(20)}$.

In environments of clinical cardiology wards, interactions have also been detected, such as the research in question. This is what the study developed in the Cardiology Department of the hospital in Pakistan shows to analyze the types of interaction, prevalence, and association of predictive factors. A total of 2,342 patients with at least 24 hours of hospitalization were investigated, most diagnosed with Myocardial Infarction (32.9\%), Coronary Artery Disease (22.7\%) and Acute Coronary Syndrome $(18.2 \%)^{(6)}$.

The presence of 5,109 potential interactions was verified, involving 53 drug pairs. 2,145 patients (91.6\%) had at least one interaction and, of these, $86.3 \%$ were patients who had interactions of greater severity, when there is a risk to life. The three most frequent interaction pairs were more severe, namely: aspirin + clopidogrel (489), clopidogrel + fondaparinoux (423), and aspirin + fondaparinoux (414) $)^{(6)}$. Patients over 60 years of age, more than seven days hospitalized, and using more than seven medications, had more risks to such interactions ${ }^{(6)}$.

Based on the potential clinical repercussions of the 22 serious drug interactions identified, the research recognized three probable cases of adverse events related to medications, which represented a frequency of $16.7 \%$. Hemorrhagic events were highlighted, such as: hematomas, epistaxis, and hematuria. These damaging effects of the interactions have still been poorly studied ${ }^{(10)}$, which limits the comparison of the results obtained; however, the production of existing knowledge signals that the occurrence of hemorrhagic events deserves the attention of the professionals who work with patients using therapy medication for cardiovascular diseases.

One of the studies that illustrates this aspect was the one that followed-up the patients admitted to the cardiology ward of an Indian teaching hospital who presented drug interactions. The research included 812 patients hospitalized for more than 48 hours, of which 249 had interactions, a prevalence of $30.47 \%{ }^{(21)}$.
The most common interactions were heparin + aspirin (29.38\%) and clopidogrel + heparin (7.21\%). From the interactions, the patients were followed-up to identify evidence of the interactions. Thus, 68 real cases were detected, with an incidence of $17.53 \%$, with bleeding being the most common adverse effect with 60 cases, mainly due to heparin and warfarin, medications originally prescribed ${ }^{(21)}$.

In Brazil, studies involving adverse drug events have been developed using the IHI methodology, but not directly related to drug interactions. It is noteworthy what was done in a public cardiological hospital to assess the occurrence of adverse events to drugs from the retrospective analysis of the medical records of 112 patients hospitalized between 2007 and 2008, with the use of 21 trackers adapted from the original IHI list ${ }^{(22)}$.

Of the patients evaluated, $69.6 \%$ had at least one tracker, of which 16 cases (14.3\%) of adverse drug events were confirmed by expert consensus. Among the events, five cases of hypoglycemia stand out, as well as three cases of hemorrhage that had suspected drugs: heparin, enoxaparin, and warfarin; two cases of hematuria due to suspected use of aspirin, clopidogrel, and enoxaparin; and two cases of hematomas caused by warfarin, clopidogrel, aspirin, and tirofiban. In $32.1 \%$ of the cases, life support interventions were required ${ }^{(22)}$.

Such adverse drug events were also characterized in a research study in a tertiary care hospital in Rio de Janeiro from a sample of 128 patient records. The researchers used trackers related to the use of drugs, laboratory tests, and signs and symptoms. There were 34 adverse events, 32 of which led to temporary harm and two that contributed to the patient's death ${ }^{(23)}$.

The estimated rate of events was 26.6 adverse events per 100 patients. The most frequent events were nausea/ vomiting with ten events, five of drowsiness, four of hypoglycemia, three of lipothymia, and two events of bleeding, renal failure, itching, and hypotension. The drug classes most involved in adverse events were those that operated on the cardiovascular system, with a frequency of $27.8 \%{ }^{(23)}$.

Considering that the serious drug interactions were identified from the pairs of drugs scheduled for the same time by the nurse, the initial problem of the research, it is necessary that these professionals use adequate criteria in the scheduling, taking into account a wide set of scheduling possibilities, in an attempt to avoid an overload of drugs scheduled for the same time and the occurrence of drug interactions. This requires investments in professional qualification.

On the other hand, in view of the therapy used and of the number of drugs that need to be prescribed due to the complexity of the clinical conditions of patients with 
cardiovascular diseases, at some point, these drugs will be found on the schedule. Therefore, it is the role of the nurse to monitor the reactions of the drugs administered and to prompt interventions, if necessary.

In this understanding, the profile of the drugs prescribed for the clients of this clinic and the adverse events detected point to the need for monitoring antihypertensive, anticoagulant, and antiplatelet drugs in terms of their interactive potential and their clinical repercussions, such as bleeding, changes in heart rate, vital signs, thrombotic events, myopathy, and rhabdomyolysis. Therefore, the possibility of such repercussions requires observation and reporting by the patient and/or caregiver about the effects of the medications administered, including responses different from the usual standard, with recording of all the appropriate monitoring parameters.

\section{$\square$ CONCLUSION}

Eighteen potential serious interactions were detected in 22 drug pairs, particularly in prescriptions with five or more drugs. The most recurrent pairs involved in serious interactions were simvastatin $x$ amlodipine and enoxaparin $x$ clopidogrel. The analysis by expert consensus defined three probable adverse events associated with potential serious drug interactions, mainly due to the presence of hemorrhagic changes in the investigated patients.

The results obtained contribute to the clinical practice in directing the assessment of the weaknesses of the medication system in the studied scenario, in view of the proposal for interventions for the safety of the medication process, especially in relation to drug interactions. Such interventions may include the following: reorganization of work processes; use of technologies to prevent interactions, such as electronic prescription alerts and use of interaction applications; permanent education of multidisciplinary teams; and greater involvement of the clinical pharmacist.

Furthermore, this knowledge contributes to the teaching of the fundamentals of nursing care, supporting discussions through the simulation of clinical cases about the scheduling of medications and the occurrence of drug interactions, so that the student develops the ability to make decisions based on clinical reasoning.

One of the limitations of the research was the number of prescriptions analyzed, which was related to the option to include only prescriptions with 48 hours of hospitalization, which restricted the findings. Another limitation of the research was the $\|\mathrm{H}\|$ methodology for screening adverse events, considering the unavailability of some trackers at the researched institution.

\section{REFERENCES}

1. World Health Organization (CH). Medication without harm: WHO's third global patient safety challenge. Geneva: WHO; 2017 [cited 2019 Jan 31]. Available from: https://apps.who.int/iris/bitstream/handle/10665/255263/WHO-HISSDS-2017.6-eng.pdf;jsessionid=1AACE861FE10068BB134FBE0E0596B55? sequence $=1$

2. Ramalingam K, Rajagopal SS, Kansamy K, Krishnan K. A prospective study on potential drug interactions among hospitalized patients in the cardiology departments in tertiary care hospitals. IJAR. 2018 [cited 2019 Jan 31];(5): 65-8. Available from: https://www.worldwidejournals.com/indian-journal-ofapplied-research-(IJAR)/fileview/May_2018_1525699051_108.pdf

3. Marques GFM, Rezende DMRP, Silva IP, Souza PC, Barborsa SRM, Penha RM, et al. Polypharmacy and potentially inappropriate medications for elder people in gerontological nursing. Rev Bras Enferm. 2018;71(5):2440-6. doi: https://doi. org/10.1590/0034-7167-2017-0211

4. Tesfaye ZT, Nedi T. Potential drug-drug interactions in inpatients treated at the Internal Medicine ward of Tikur Anbessa Specialized Hospital. Drug Health Patient Saf. 2017;9:71-6. doi: https://doi.org/10.2147/DHPS.S126336

5. Malachias MVB, Plavnik FL, Machado CA, Malta D, Scala LCN, Fuchs S. 7th Brazilian Guideline of Arterial Hypertension - Chapter 1: Concept, Epidemiology and Primary Prevention. Arq Bras Cardiol 2016;107(3Suppl.3):1-6. doi: https:// doi.org/10.5935/abc.20160151

6. Murtaza G, Khan MYG, Azhar S, Khan SA, Khan TM. Assessment of potential drug-drug interactions and its associated factors in the hospitalized cardiac patients. Saudi Pharm J. 2016;24(2):220-5. doi: https://doi.org/10.1016/j. jsps.2015.03.009

7. Saleem A, Masood I, Khan TM. Clinical relevancy and determinants of potential drug-drug interactions in chronic kidney disease patients: results from a retrospective analysis. Integr Pharm Res Pract. 2017;6:71-7. doi: https://doi. org/10.2147/IPRP.S128816h

8. Veloso RCSG, Figueredo TP, Barroso SCC, Nascimento MMG, Reis AMM. Factors associated with drug interactions in elderly hospitalized in high complexity hospital. Ciênc Saúde Coletiva. 2019;24(1):17-26. doi: https://doi. org/10.1590/1413-81232018241.32602016

9. Pinto NBF, Vieira LB, Pereira FMV, Reis AMM, Cassiani SHB. Drug interactions in prescriptions for elderly hypertensive patients: prevalence and clinical significance. Rev Enferm UERJ. 2014;22(6):735-41. doi: https://doi.org/10.12 957/reuerj.2014.7111

10. Zheng WY, Richardson LC, Li L, Day RO, Westbrook Jl, Baysari MT. Drug-drug interactions and their harmful effects in hospitalised patients: a systematic review and meta-analysis. Eur J Clin Pharmacol. 2018;74(1):15-27. doi: https:// doi.org/10.1007/s00228-017-2357-5

11. Henrique DM, Silva LD, Camerini FG, Andrade KBS, Pereira SEM, Fassarella CS. Safe opioid analgesic therapy dose scheduling for burn patients: a cross-sectional study. Rev Enferm UERJ. 2017;25:e28082. doi: https://doi. org/10.12957/reuerj.2017.28082

12. Ribeiro GSR, Camerini FG, Henrique DM, Almeida LF, Pereira LMV, Macedo MCS. Analysis of nursing scheduling in an ICU: focus on patient safety. Rev Fund Care Online. 2018;10(2):510-5. doi: https://doi.org/10.9789/2175-5361.2018. v10i2.510-515 
13. Ministério da Saúde (BR). Agência Nacional de Vigilância Sanitária. Assistência segura: uma reflexão teórica aplicada à prática. 1a ed. Brasília; 2013 [cited 2018 Jul 03]. Available from: https://www20.anvisa.gov.br/ segurancadopaciente/index.php/publicacoes/item/caderno-1-assistenciasegura-uma-reflexao-teorica-aplicada-a-pratica

14. Fontenele RE, Araújo TL. Análise do planejamento dos horários de administração de medicamentos em unidade de terapia intensiva cardiológica. Rev Enferm UERJ. 2006 [cited 2018 Nov 15];14(3):342-9. Available from: http://www. facenf.uerj.br/v14n3/v14n3a03.pdf

15. Micromedex Healthcare Series [Internet]. Greenwood Village (US): Thomson Reuters; 2016 [cited 2016 Sep 10]. Available from: www.periodicos.capes. gov.br

16. Griffin FA, Resar RK. IHI Global Trigger Tool for measuring adverse events. $2^{\text {nd }}$ edition. Cambridge (MA): Institute for Healthcare Improvement; 2009 [cited 2019 Jan 31]. Available from: http://app.ihi.org/webex/gtt/ihiglobaltriggerto olwhitepaper2009.pdf

17. Giordani F, Rozenfeld S, de Oliveira DFM, Versa GLGS, Terencio JS, Caldeira LF, et al. Vigilância de eventos adversos a medicamentos em hospitais: aplicação e desempenho de rastreadores. Rev Bras Epidemiol. 2012;15(3):455-67. doi: https://doi.org/10.1590/S1415-790X2012000300002
18. Naranjo CA, Busto U, Sellers EM, Sandor P, Ruiz I, Roberts EA, et al. A method for estimating the probability of adverse drug reactions. Clin Pharmacol Ther. 1981;30(2):239-45. doi: https://doi.org/10.1038/clpt.1981.154

19. Shakeel F, Khan JA, Aamir M, Hannan PA, Zehra S, Ullah I. Risk of potential drugdrug interactions in the cardiac intensive care units: a comparative analysis between 2 tertiary care hospitals. Saudi Med J. 2018;39(12):1207-12. doi: https://doi.org/10.15537/smj.2018.12.23430

20. Jain S, Jain P, Sharma K, SaraSwat P. A prospective analysis of drug interactions in patients of intensive cardiac care unit. J Clin Diagn Res. 2017;11(3):FC01FC04. doi: https://doi.org/10.7860/JCDR/2017/23638.9403

21. Patel VK, Acharya LD, Rajakannan T, Mallayasamy S, Guddttu V, Padmakumar R. Potential drug interactions in patients admitted to cardiology wards of a south Indian teaching hospital. AMJ. 2011;4(1):9-14. doi: https://doi.org/10.4066/ AMJ.2011.450

22. Roque KE, Melo ECP. Avaliação dos eventos adversos a medicamentos no contexto hospitalar. Esc Anna Nery. 2012;16(1):121-7. doi: https://doi.org/10. 1590/S1414-81452012000100016

23. Rozenfeld S, Giordani F, Coelho S. Adverse drug events in hospital: pilot study with trigger tool. Rev Saúde Pública. 2013;47(6):1102-11. doi: https://doi.org/ 10.1590/S0034-8910.2013047004735

\section{- Corresponding author:}

Rafael Celestino da Silva

E-mail: rafaenfer@yahoo.com.br

Editor-in-chief:

Maria da Graça Oliveira Crossetti 